\title{
EL CONOCIMIENTO HABITUAL COMO CONDICIÓN DE POSIBILIDAD DE LA METAFÍSICA
}

\section{THE HABITUAL KNOWLEDGE AS CONDITION OF THE POSSIBILITY OF METAPHYSICS}

\author{
Miguel Martí Sánchez \\ Universidad de Navarra (España)
}

Recibido: 10-10-2014

Aceptado: 02-11-2014

Resumen: Para Polo la metafísica es un saber radical de principios. Se examina ésta definición y se la confronta con posibles objeciones inherentes a la nociones de 'principio’ y de ‘conocimiento'. Se exponen cuatro posibles objeciones: 1) ¿cómo puede ser algo un principio y no ser evidente sino necesitar de un saber sobre él? 2) Si son las cosas las que son primeras, ¿cómo se ha llegado a tener un cierto conocimiento de 'principios'? 3) Si nuestro saber es de cosas, ¿cómo podría darse un saber discursivo sobre principios? Y 4) ¿no obligaría un saber de principios a abandonar cualquier otro conocimiento previo? Para hacer frente a éstas aporía se acude sobre todo a algunas propuestas desarrolladas en su Curso de Teoría del Conocimiento. En especial a la diferencia entre carácter intencional del conocimiento objetivo y el habitual del conocimiento de principios.

Palabras-clave: intelecto, conocimiento objetivo, conocimiento habitual, objeto, principio, aporía.

Abstract: According to Polo Metaphysics is a radical knowledge of principles. This definition is examined and confronted with some difficulties associated with the concepts of 'principle' and 'knowledge'. There are four objections: 1) How can a principle be primary and not be at the same time manifest? 2) Why could one understand what are 'principles' if one have only experience of things? 3) If our knowledge and language are dealing always only with things, how would be possible a discursive science about principles? And 4) If there is a science of principles, why do not abandon the previous knowledge of things? In order to solve these problems we shall use some arguments in the Curso de Teoria del Conocimiento. The main argument is that there is a difference between the intentionality as a principal characteristic of the knowledge of objects, and the knowledge by intellectual habits in order to understand the principles.

Key-words: intellect, knowledge of objects, knowledge by habits, object, principle, puzzle. 
En las páginas que siguen se exponen algunas de las ideas de Leonardo Polo acerca de la metafísica como ciencia o saber de los principios de la realidad. Es propio de la metafísica preguntarse por su propio método, porque un saber acerca de las causas últimas no puede apoyarse en conocimientos secundarios o derivados, pues su método debe ser tan radical como los principios que quiere conocer. Polo reflexionó a menudo sobre estos asuntos ${ }^{1}$. Mediante esta nota se busca condensar algunas de esas propuestas con el fin de responder a ciertas paradojas asociadas a la misma posibilidad de la metafísica. Para ello se acude sobre todo al Curso de Teoría del Conocimiento.

Metafísica significa para Polo el saber cultivado a partir de los presocráticos pero que se fragua ante todo con Platón y Aristóteles, y que por mero afán de saber busca dar cuenta de los principios y/o causas últimas de aquello que es (tò òn) mediante la inteligencia (noûs) ${ }^{2}$.

La metafísica nace asociada a la paradoja de que se trata de un saber inútil $^{3}$. Esto se debe, entre otras razones, a que no se ocupa con cosas, sino con principios. De modo que la metafísica sería una ciencia que no tiene como punto de partida a las cosas (los entes) sino principios. Ahora bien, hay varios problemas o aporías ligadas a esta definición, en especial por lo que se refiere al uso que en ella se hace del término 'principio'. Pueden ordenarse de la siguiente manera: en primer lugar, (a) si realmente estos principios fuesen principios, es decir primeros u originarios, deberían ser también evidentes, pero ¿qué necesidad habría entonces de un saber o ciencia acerca de ellos? En segundo lugar, (b) si se admite que -por la objeción (a)- son las cosas las que son primeras ¿cómo se ha llegado a saber -en el sentido de tener noticia- de algo así como de principios? Es claro que tanto la noción de principio(s) real(es) como la idea de una ciencia acerca de ellos resultarían, en este caso, cuanto menos paradójicas.

A estos dos problemas asociados a la noción de 'principio' se unen los que se refieren a la relación del conocimiento de cosas y, si es que lo hubiese,

[1] Polo, L.: El acceso al ser. Pamplona: Eunsa, 2004²; El ser: Tomo I. Pamplona: Eunsa, 19972; Hegel y el Posthegelianismo. Pamplona: Eunsa, 2006²; Evidencia y realidad en Descartes. Pamplona: Eunsa, 200733 Nominalismo, idealismo y realismo. Pamplona: Eunsa, 2006 son lugares donde pueden encontrarse estas reflexiones. En la última obra nombrada es donde mejor puede verse el desarrollo de estos temas según Polo. Aparecen de manera literal muchas de las tesis aquí sostenidas, por ejemplo, la diferencia entre conocimiento objetivo y conocimiento habitual, y la diferencia entre el objeto como primero y los principios como primarios (aquello más allá de lo cual no hay nada).

[2] Cfr. Polo, L.: Curso de Teoría del Conocimiento. Vol. II, Pamplona: Eunsa, 2006, lecciones 12 y 13 especialmente.

[3] Para las comparaciones que hace Polo entre metafísica y otras formas de saber puede verse su último libro publicado: Polo, L.: Epistemología, creación y divinidad. Pamplona: Eunsa, 2014. A esta paradoja de un saber inútil o sin producto (por oposición a las téckne), aunque en relación al saber que llama sophrosine, parece llegar Platón en su diálogo Cármides.

THÉMATA. Revista de Filosofía, №50 julio-diciembre (2014) pp.: 295-302 doi: 10.12795/themata.2014.i50.14 
el conocimiento de principios. Por un lado, y en nuestro orden en tercer lugar, (c) está la aporía referida a la posibilidad del mismo discurso metafísico. Ciertamente para hablar de aquello más inmediato y real -lo que serían los principios- no queda más remedio que dar un rodeo a base de mediaciones, un caso de las cuales paradigmático es el lenguaje ${ }^{4}$. ¿Cómo es esto posible? ¿No sería en ese caso necesario apelar a un saber de tipo místico? Y por último, como cuarta paradoja, (d) si se quiere alcanzar ese saber de los principios, parece ineludible renunciar al conocimiento primario o cotidiano, que podemos llamar también de cosas u objetos. Ahora bien, ¿por qué se debe renunciar a un conocimiento sin el cual hubiese sido imposible hacer un contraste entre objetos o cosas y principios?

Como resumen puede decirse que desde su nacimiento a la metafísica -entendida como saber de principios- le acompañan por lo menos estas cuatro aporías:

(a) Nace como un saber acerca de los principios reales, pero prima facie los principios no son primeros y tampoco por tanto reales, más bien son las cosas aquello que es primero y real.

(b) Las cosas se imponen -según (a)- como lo único real, luego ¿de dónde surge algo así como la necesidad de apelar a principios reales?

(c) ¿Cómo es posible desarrollar un saber acerca de esos principios si siempre pensamos y hablamos de cosas?

(d) Y en el caso de que hubiese principios, sería necesario renunciar al conocimiento de objetos y cosas con el que se conoce de manera ordinaria.

Una vez enumeradas algunas de las dificultades relacionadas estrechamente con la misma problemática metafísica cabe preguntarse entonces por cuál es el camino -si es que lo hay- que es necesario recorrer para desarrollar un saber acerca de los primeros principios. Con el fin de responder, en la medida de lo posible, a esta pregunta, y evitar que uno se detenga en la perplejidad a la que suelen llevar algunas tesis metafísicas -como puede ocurrir con el mismo conocimiento de los primeros principios-, acudiré a algunas de las propuestas de Polo, como ya se ha dicho, sobre todo a las consignadas en su Curso de Teoría del Conocimiento. Son las siguientes: 1) conocer es una actividad u operación vital del ser humano; 2) la inteligencia conoce de modo plural, potencialmente infinito y ordenada al crecimiento; 3) una cosa es el conocimiento (objetivo y habitual), otra la teoría del conocimiento y la metafísica; y 4) la metafísica es un saber acerca de principios pero diferenciado del que tienen de ellos otros saberes.

[4] De todos modos conviene no confundir el conocimiento de los principios con el discurso que se elabora para dar cuenta de qué son estos principios o de que es posible conocerlos. Pueden verse valiosas reflexiones sobre las relaciones de mediación-inmediación en la temática metafísica en el libro Metafísica tras el final de la metafísica de Alejandro Llano y Fernando Inciarte (Ediciones Cristiandad, Madrid 2007).

THÉMATA. Revista de Filosofía, $\mathrm{N}^{\circ} 50$ julio-diciembre (2014) pp.: 295-302 doi: 10.12795/themata.2014.i50.14 


\section{Conocer es una actividad vital del ser humano}

Conocer para el ser humano no es una actividad extrínseca o accidental, sino una de sus actividades más propias, en la que expresa de manera íntima su esencia y se le revela también la esencia de aquello que propiamente es, lo que se llama realidad. Más aún, conocer es una actividad que ejerce en cuanto que es un ser vivo intelectual, por eso Polo suele decir que el conocimiento es la más alta operación vital ${ }^{5}$. Por consiguiente conviene que un saber acerca de los principios no ignore que él mismo -en cuanto 'saber'-es en parte conocimiento. Esto último equivale a decir que tanto las cosas como los principios cuando se muestran lo hacen a un cognoscente.

De entrada, como decimos, la relación del ser humano con los principios, o mejor, con las cosas, es vital y cognoscitiva. Y es al conocimiento -sobre todo intelectual- al que se le muestran tanto las cosas como, si es que los hubiese, los principios de las mismas. De modo que una vez se produce esa relación entre conocimiento y realidad no puede evitarse tenerla en cuenta como un dato fundamental; más aún cuando lo que se busca es dar cuenta desde el conocimiento -en el cual el ser humano siempre se encuentra- de aquella realidad con la que se encuentra en relación.

Por consiguiente en el caso de buscar un conocimiento radical de lo real -metafísico-, no se puede pasar por alto que el conocimiento siempre media entre lo que se conoce y aquel que ejerce ese conocimiento. Ahora bien eso no significa que se encuentren en una relación biunívoca o isomórfica, pues el conocimiento humano siempre se expresa de manera plural y concreta. Es lo que Polo llama la conmensuración de operación(es) y objeto(s), e ilustra con la pluralidad de operaciones intelectuales que ya había distinguido la tradición ${ }^{6}$ tanto griega como sus receptores medievales: abstracción, conciencia y juicio.

Pues bien si se advierte que conocer y conocido no son idénticos se está, según Polo, en situación de hacer metafísica. Una vez se conoce la diferencia entre ser-conocido y ser-conocido entonces al mismo tiempo se atisba la naturaleza de la problemática metafísica ${ }^{7}$. En el momento de la vida intelectual en que se comprueba que el conocimiento cotidiano no basta porque no agota lo que puede saberse de lo real, entonces se busca fundamentar ese mismo conocimiento. Esto ocurre, como se decía, porque se cae en la cuenta de que el conocimiento de la realidad no es la realidad misma.

[5] Esta expresión la usa Polo en varios lugares, el más claro se encuentra en Polo, L.: Presente y futuro del hombre. Madrid: Rialp, $2012^{2}$.

[6] Puede verse para este desarrollo de las operaciones intelectuales en la tradición y sobre todo en Aristóteles la profunda monografía de Kapp, E.: Greek Foundations of Traditional Logic. New York: Columbia University Press, 1967.

[7] Cfr. Polo, L.: "Lo intelectual y lo inteligible" en Anuario Filosófico 15, 1982, pp. 103-132.

THÉMATA. Revista de Filosofía, Nº50 julio-diciembre (2014) pp.: 295-302 doi: 10.12795/themata.2014.i50.14 
Para fundamentar nuestro conocimiento es claro que no es posible salir del conocimiento, pero tampoco -si se aspira a un saber radical- puede uno quedarse sin más en él. La solución de Polo -inspirada en argumentos ya formulados por Tomás de Aquino ${ }^{8}$ - consiste en declarar que ese reconocimiento de la limitación inherente al conocimiento objetivo o cotidiano es sobre todo un autoconocimiento. A juicio del pensador madrileño el conocimiento es acto perfecto, y por ello alcanza siempre y en todo momento su fin. Pero el conocimiento se expresa no sólo mediante un único acto, sino con múltiples. Sin advertir esa multiplicidad de la intelección, y por tanto también la existencia de una pluralidad de objetos de la intelección cualitativamente distintos, no cabe diferenciar entre objeto y realidad, y tampoco, en definitiva, entre cosa y principio. De modo que, como se verá más adelante, en cierto sentido conocer los principios es ante todo conocerse, y sólo en esa medida es posible que a uno se le revele tal y como es aquello que conoce ${ }^{9}$.

\section{La inteligencia conoce de modo plural, potencialmente infini- to y ordenada al crecimiento}

Como ya se ha dicho, no hay un único modo o método de conocer según el cual no hiciese falta seguir conociendo, con otras palabras: el conocimiento se expresa de manera plural. Por lo mismo no hay un último objeto de conocimiento. Como repite Polo a menudo, se conoce y se sigue conociendo. Sólo al ser humano, a diferencia del resto de seres naturales, se le abre el mundo como objeto $^{10}$, y en la medida en que el objeto es lo abierto, cuando el ser humano conoce lo que conoce -objetos- ni siquiera nota su presencia. Ahora bien, asegura Polo que cabe volver sobre tal presencia del objeto, la cual, sin embargo, no es parte ni nota del objeto en cuanto tal. Este conocimiento de la presencia o bien reconocimiento, propone Polo, no es de carácter objetivo sino habitual.

La noción de hábito (héxis-hábitus) tiene un largo recorrido histórico -en especial en lo que concierne a la voluntad y por tanto a la ética y filosofía

[8] Cfr. Tomás de Aquino, De veritate, q. 1, a. 9.

[9] No se olvide que ese reconocimiento puede verse desde tres perspectivas: 1) una la de la existencia de ese reconocimiento en cualquier acto "natural" del entendimiento o intelecto (cualquiera sabe que su conocimiento no es la realidad), en segundo lugar, 2) ese reconocimiento en cuanto que es hecho tema (por ejemplo, formular como tesis de la teoría del conocimiento: "sin acto de reflexión el acto intelectual de juzgar es imposible"), pues en ese caso es parte de la teoría del conocimiento; y por último, 3) ese saber de la necesidad de reconocer la limitación del conocimiento cotidiano con el fin de hacer metafísica. En esta última se encuentra la propuesta metódica de Polo para la temática metafísica: primera dimensión del abandono del límite mental.

[10] En esto, como en otros asuntos, Polo es netamente aristotélico. Para esto puede verse el estudio de González Ginocchio, D.: El acto de conocer. Antecedentes aristotélicos de Leonardo Polo. Pamplona: Cuadernos de Anuario Filosófico, Serie Universitaria, 183, Servicio de Publicaciones Universidad de Navarra, 2005.

THÉMATA. Revista de Filosofía, №50 julio-diciembre (2014) pp.: 295-302 doi: 10.12795/themata.2014.i50.14 
práctica-, que no es el momento de desarrollar. La intención de Polo es rescatar este concepto para expresar el modo en que la inteligencia -y no sólo la voluntad- es capaz de ejercer pluralidad de actos, y sobre todo, de reconocerse, perfeccionarse y crecer $^{11}$. Le interesa mostrar cómo la inteligencia llega a ser lo que es -entre otras cosas, capaz de conocer principios y no sólo cosas- sin prescindir de ninguna de sus capacidades y modalidades. De ahí que con el uso del término hábito se busque ante todo una descripción fiel de cómo funciona la inteligencia. Ésta conoce objetos, pero también reconoce su actividad más propia: actos cuyos objetos son intencionales - sin los cuales no habría conocimiento-; pero esa advertencia no corre ni puede correr a cargo de la misma operación que presenta al objeto, sino de un acto de otra índole que ilumina la operación ${ }^{12}$.

En resumen, el conocimiento humano se manifiesta como una realidad plural, no ejerce sólo un tipo de actos, sino que al conocimiento objetivo y cotidiano le acompaña un conocer de carácter habitual. Los hábitos iluminan la operación, y en esa medida muestran al mismo tiempo la natura intellectualis del ser humano. Sin esa duplicidad inherente al conocimiento -operación y hábito- sería imposible diferenciar entre cosa y principio, entre saber y no saber, entre verdadero y falso, realidad y apariencia, y en último extremo sería irrealizable la metafísica.

\section{Diferencias entre conocimiento cotidiano (objetivo y habi- tual), teoría del conocimiento y metafísica}

Polo distingue claramente entre el conocimiento humano, que considera capaz de objetos, operaciones y hábitos, de la teoría que hacemos sobre ese conocimiento y, por último, de un camino del conocimiento humano para conocer los principios: la metafísica. Por esa razón, que como resultado de su investigación Polo diga que la posibilidad de la metafísica se cifra en los hábitos -sin ellos no hay posibilidad de advertencia de la diferencia entre operación y objeto ni entre la presencia y lo presentado- no significa que sin metafísica no haya conocimiento de ningún tipo.

Para conocer las esencias de las cosas no hace falta saber metafísica, más bien al revés, tanto para hacer teoría del conocimiento como metafísica es necesario haber conocido. Ahora bien, según Polo, no basta ese haber conocido para hacer metafísica y tampoco para hacer teoría del conocimiento. Pues sólo

[11] "La inteligencia no es un principio fijo": Polo, L.: Curso cit., vol. II, p. 170.

[12] No se trata de una solución ad hoc. Como ya se ha citado, el mismo Aquinate piensa que no es posible el ejercicio del acto intelectual de juzgar sin que el entendimiento conozca en cierto sentido su esencia a través de su acto. La cuestión reside en qué tipo de conocimiento es el que acompaña al acto de juzgar y que revela al mismo tiempo la esencia del entendimiento. Según Polo tal conocimiento es ante todo habitual.

THÉMATA. Revista de Filosofía, №50 julio-diciembre (2014) pp.: 295-302 doi: 10.12795/themata.2014.i50.14 
la primera advierte la insuficiencia de ese conocimiento en orden al saber de los principios, y es gracias a la segunda que es posible describir en qué consiste esa insuficiencia. De ahí que quepa decir que el saber metafísico no es conocimiento de hábitos sino por medio de hábitos. Y que la teoría del conocimiento -al menos en su vertiente dedicada a la inteligencia- no es ejercicio de hábitos sino descripción tanto de ellos como del resto de actos intelectuales ${ }^{13}$.

\section{La metafísica es un saber acerca de principios pero diferen- ciado del que tienen de ellos otros saberes}

La metafísica se caracteriza respecto de otro tipos de saberes también dedicados al tema del fundamento en que busca dar cuenta de éste sin mediaciones, es decir, sin otro recurso que la inteligencia. En cuanto que la inteligencia conoce de manera intencional tiene garantizado que su objeto es siempre de lo real. Además, ese mismo detenerse propio de la inteligencia, por el que cae en la cuenta de que hay algo más que objeto -es decir, saber que hay algo más que lo que se muestra en la intencionalidad-, es lo que inicia la búsqueda de principios. A la inteligencia se le muestra esa limitación inherente a la intencionalidad $^{14}$, lo que no significa que no se muestre a otras facultades humanas, como puede ser la voluntad. Pero es la metafísica la que es ante todo ejercicio de la inteligencia en orden a buscar un saber acerca del fundamento.

En cuanto que se pregunta por la índole del fundamento, la metafísica renuncia a dominar al fundamento y a apelar a instancias inferiores a la inteligencia misma con el fin de conocerlo. Pues, como se ha dicho, empezar a hacer metafísica es caer en la cuenta de que los objetos no son reales o no son todo lo real. De modo que hay algo que no aparece en el objeto ni como objeto, y sin embargo eso también es real, incluso lo más real. Luego el objeto no es la causa última pues siempre hay algo más que objeto. De este modo se descubre que son los principios los que preceden a la inteligencia, pues ia qué cabría entonces apelar más que a la misma inteligencia que ha revelado tal anterioridad?

Es a partir de aquí desde donde uno puede hacerse la pregunta por los principios, es decir, en el momento en que aquello que parecía indubitable y evidente -el objeto, "las cosas", lo que hay ya inmediatamente abierto- se mues-

[13] Me permito remitir a un trabajo en el que he desarrollado un poco más estas ideas: Martí, M.: "Intencionalidad: relación entre conocimiento objetivo y teoría" en González, A. L. y González, D.: Pensamiento, lenguaje y realidad. Estudios sobre la filosofía de Leonardo Polo. Pamplona: Cuadernos de Pensamiento Español 47, Servicio de Publicaciones de la Universidad de Navarra, 2012, pp. 13-20.

[14] Nótese que es la inteligencia misma la que es capaz de ello, y no determinadas inteligencias como las de grandes pensadores, o bien sólo a una determinada rama de la filosofía o escuela filosófica. Lo contrario sería algo así como proponer un cierto esoterismo filosófico.

THÉMATA. Revista de Filosofía, №50 julio-diciembre (2014) pp.: 295-302 doi: 10.12795/themata.2014.i50.14 
tra como algo aspectual y parcial ${ }^{15}$. Esa capacidad de mostrar el conocimiento intencional como algo limitado es parte integrante de la inteligencia, un momento de su desenvolvimiento natural en cuanto ordenada al conocimiento habitual y de principios.

La metafísica que se entiende a sí misma como saber de principios renuncia a reducir la realidad a la concepción cotidiana que tenemos de ella. No lo hace porque piense que ésta es falsa, sino porque con ella no es capaz de justificar aquello que se le ha aparecido como real. El juicio de la inteligencia es contundente: hay más realidad que la que se muestra a la manera cotidiana de conocer. No porque haya otra realidad, sino porque es esa misma cotidianeidad la que es necesario justificar. El metafísico afirma que realmente no sabe qué es la realidad, de modo que renuncia a la seguridad de la ignota ignorantia y busca el fundamento. Puede decirse entonces, de manera dialéctica, que hacer metafísica consiste en pasar del saber 'no sabido' -concepción natural- al no saber 'sabido' -advertencia de la limitación inherente al conocimiento objetivo-, e intentar alcanzar el saber 'sabido'-metafísica-.

Como conclusión de esta nota pueden resumirse las propuestas de solución de Polo -desarrolladas a lo largo del texto- a las aporías planteadas al comienzo:

1) Hay dos maneras de decir que algo es primero para el conocimiento, a saber: o bien objetivo, o bien habitual. Ahora bien, lo que se le muestra como primero a los hábitos cognoscitivos desbanca de su anterioridad óntica a aquello que se le mostraba como anterior u originario al conocimiento objetivo. Algo parecido a lo que ocurre, en la descripción que suele hacerse en la teoría de la ciencia (episteme) aristotélica cuando se diferencia entre el conocimiento de lo que es primero para nosotros (pròs hemás) y lo que lo es de manera absoluta (haplôs).

2) El descubrimiento de la intencionalidad como rasgo característico del conocimiento objetivo muestra también que cualquier objeto intelectual es insuficiente para dar cuenta de sí mismo, es decir, tanto de lo que muestra como de su presencia ante el cognoscente. Es necesario justificarlo, es decir, buscar su fundamento o principio.

3) El proceso de reconocimiento o autoconocimiento de la inteligencia es la condición de posibilidad de la distinción entre cosas y principios. Una vez desvelada la 'existencia' de operaciones que hacen posibles los objetos, se cae en la cuenta de la parcialidad inherente a cualquier objeto y a cualquier operación.

4) Por consiguiente, aunque se trata de renunciar al conocimiento cotidiano, no se hace con el fin de suplantar tal conocimiento, sino de fundamentar aquel que se posee y que se muestra como limitado y parcial.

[15] Obsérvese que no se dice falso o erróneo. Ese conocimiento, a pesar de ser aspectual, no deja de ser intencional y en ese sentido verdadero.

THÉMATA. Revista de Filosofía, №50 julio-diciembre (2014) pp.: 295-302 doi: 10.12795/themata.2014.i50.14 